\title{
Cerebral depression due to propylene glycol in a patient with chronic epilepsy - the value of the plasma osmolal gap in diagnosis
}

\author{
Y. Lolin, ${ }^{1}$ D.A. Francis, ${ }^{2}$ R.J. Flanagan, ${ }^{3}$ P. Little, ${ }^{1 *}$ P.T. Lascelles ${ }^{1}$ \\ ${ }^{1}$ Department of Chemical Pathology and ${ }^{2}$ Department of Neurology, National Hospital for Nervous \\ Diseases, Queen Square, London WC1N $3 B G$ and ${ }^{3}$ Poisons Unit, New Cross Hospital, Avonley Road, \\ London SE14 SER, UK.
}

\begin{abstract}
Summary: A case of propylene glycol poisoning is described in a 39 year old woman which resulted in her admission to hospital in status epilepticus. She had had a long-standing history of uncontrollable epilepsy. The diagnosis of propylene glycol poisoning resulted directly from the finding of a high plasma osmolal gap on admission. This finding would have been missed if later samples only had been analysed. Plasma osmolality and the osmolal gap should be considered first line investigations in patients presenting with metabolic acidosis and cerebral signs and symptoms. Since her discharge from hospital a year ago the patient has had no further seizures.
\end{abstract}

\section{Introduction}

Propylene glycol (1,2-propanediol) is an organic solvent widely used in the pharmaceutical and food industries, and in agriculture. ${ }^{1,2}$ Few cases of poisoning have been described, and serious toxic effects include raised plasma osmolality, lactic acidosis, intravascular haemolysis, cerebral depression, seizures and cardiorespiratory arrest. ${ }^{2-7}$ In all but one case, ${ }^{5}$ the source of propylene glycol was directly related to its use as a solvent in medication. We describe a case of propylene glycol poisoning in a patient with long-standing epilepsy.

\section{Methods}

The plasma and urine ethanol and propylene glycol were measured by gas-liquid chromatography (limit of detection $0.1 \mathrm{~g} / 1$ for both $)^{8}$ and the identification of propylene glycol was confirmed by GC-MS (LKB 9000). A general drug screen was performed by colour tests, thin layer and gas chromatography.

Correspondence: Y. Lolin L.R.C.P., M.R.C.S., M.Sc.

*Present address: Department of Chemical Pathology, Westminster Hospital, Page Street, London SW1P 2AN, UK

Accepted: 15 March 1988
The plasma osmolarity $(\mathrm{mmol} / \mathrm{l})$ was calculated using the formula: Plasma osmolarity $=1.86 \times \mathrm{Na}$ $(\mathrm{mmol} / \mathrm{l})+$ plasma urea $(\mathrm{mmol} / \mathrm{l})+$ plasma glucose $(\mathrm{mmol} / \mathrm{l}){ }^{3,9}$ The plasma osmolality was measured by freezing point depression (Roebling Osmometer, W. Germany).

The osmolal gap $\left(\mathrm{mmol} / \mathrm{kg} \mathrm{H}_{2} \mathrm{O}\right)$ was calculated using the formula: Osmolal gap = plasma osmolality-(plasma osmolarity/0.93). ${ }^{3}$

\section{Case report}

A 39 year old unmarried woman had been well up to the age of 16 years, when frequent generalized seizures developed. These episodes were preceded by a feeling of fear or auditory hallucinations and lasted up to one hour with loss of consciousness. They persisted throughout early adult life, despite treatment with phenobarbitone, phenytoin and sulthiame. In January 1986, her medication was changed to phenytoin $500 \mathrm{mg}$ daily, sodium valproate $1 \mathrm{~g}$ twice daily, and clobazam $20 \mathrm{mg}$ daily. She had fewer fits, but was admitted several times to hospital in status epilepticus, for which no apparent precipitating event was found. During these admis-

(C) The Fellowship of Postgraduate Medicine, 1988 
Table I The biochemical data obtained from the $10.00 \mathrm{~h}, 13.00 \mathrm{~h}$ and the $16.00 \mathrm{~h}$ blood samples on the day of admission

\begin{tabular}{|c|c|c|c|c|}
\hline \multirow[b]{2}{*}{ Analyte } & \multicolumn{3}{|c|}{ Time of sample } & \multirow[b]{2}{*}{ Reference range } \\
\hline & $10.00 \mathrm{~h}$ & $13.00 \mathrm{~h}$ & $16.00 h$ & \\
\hline \multicolumn{5}{|l|}{ Plasma } \\
\hline $\mathrm{Na}^{+}(\mathrm{mmol} / \mathrm{l})$ & 140 & & 138 & $132-144$ \\
\hline $\mathrm{K}^{+}(\mathrm{mmol} / \mathrm{l})$ & 3.4 & & 3.6 & $3.5-5.0$ \\
\hline Urea $(\mathrm{mmol} / \mathrm{l})$ & 3.5 & & 4.1 & $2.5-6.7$ \\
\hline Glucose $(\mathrm{mmol} / \mathrm{l})$ & 5.4 & & 5.8 & $3.3-9.0$ \\
\hline Propylene glycol $(\mathrm{g} / \mathrm{l})$ & 4.0 & & $<0.1$ & \\
\hline Ethanol $(\mathrm{g} / \mathrm{l})$ & 0.9 & & not measured & \\
\hline Osmolality $(\mathrm{mmol} / \mathrm{kg})$ & 340 & & 296 & $280-300$ \\
\hline Osmolarity $(\mathrm{mmol} / \mathrm{l})$ & 269 & & 267 & \\
\hline Osmolal gap $(\mathrm{mmol} / \mathrm{kg})$ & 51 & & 9 & $<10$ \\
\hline \multicolumn{5}{|l|}{ Serum } \\
\hline Lactate $(\mathrm{mmol} / \mathrm{l})$ & & & 0.43 & $<1.8$ \\
\hline Pyruvate (mmol/l) & & & 0.043 & $0.45-0.080$ \\
\hline \multicolumn{5}{|l|}{ Arterial blood } \\
\hline $\mathrm{pH}$ & 7.39 & 7.29 & & $7.37-7.42$ \\
\hline $\mathrm{PO}_{2}(\mathrm{kPa})$ & 10.7 & 30.8 & & $11.3-12.6$ \\
\hline $\mathrm{PCO}_{2}(\mathrm{kPa})$ & 4.4 & 5.5 & & $4.86-5.94$ \\
\hline $\mathrm{HCO}_{3}(\mathrm{mmol} / \mathrm{l})$ & $\begin{array}{l}19.6 \\
\text { (on air) }\end{array}$ & $\begin{array}{c}18.0 \\
\left(\text { on } \mathrm{O}_{2}\right)\end{array}$ & & $21.3-24.8$ \\
\hline
\end{tabular}

sions she had several episodes of apnoea and respiratory arrest, and required ventilation. The electroencephalogram (EEG) during the seizures showed a widespread post-central delta rhythm of $2-6 \mathrm{~Hz}$, but no focal spike or complex waveforms.

Six months later she was again admitted in status epilepticus. On admission at $10.00 \mathrm{~h}$ she was stuporose with repetitive generalized convulsions. The results of routine haematological and biochemical investigations were within normal limits and the serum anticonvulsant drug levels were within the therapeutic ranges. The EEG showed no evidence of epilepsy. An hour after her admission she was having episodes of hypoventilation with periods of apnoea lasting 10-20 seconds and required assisted ventilation. Despite intravenous diazepam, fitting continued, and a chlormethiazole infusion was started. At $13.00 \mathrm{~h}$ she was noted to have a metabolic acidosis (Table I). Subsequently the fits became much less frequent, and by $16.00 \mathrm{~h}$ she was responsive to verbal commands. The relatively rapid recovery from status epilepticus and the unexplained metabolic acidosis raised the suspicion of a drug overdose. The serum lactate, pyruvate, electrolytes and plasma osmolalities were measured and the osmolal gap calculated on the $10.00 \mathrm{~h}$ and $16.00 \mathrm{~h}$ samples (Table I). Both plasma samples and the $10.00 \mathrm{~h}$ urine sample were screened for drugs and poisons, especially alcohols. Large amounts of propylene glycol $(4.0 \mathrm{~g} / \mathrm{l})$ and ethanol $(0.9 \mathrm{~g} / \mathrm{l})$ were found in the $10.00 \mathrm{~h}$ plasma. Propylene glycol $(0.1 \mathrm{~g} / \mathrm{l}$ was also found in the $10.00 \mathrm{~h}$ urine sample, but was less than $0.1 \mathrm{~g} / 1$ in the $16.00 \mathrm{~h}$ plasma.

The patient recovered fully over the next 24 hours and consistently denied ingestion of ethanol or of any other unusual substances. She consented to a search of her home for a possible source of propylene glycol. Fifteen substances including her anti-epileptic medication were analysed for alcohols. Propylene glycol $(0.6 \mathrm{~g} / \mathrm{l})$ was found in a carton of fruit juice and ethanol $(30 \%)$ in a mouth wash. The patient denied ingestion of either of these two liquids prior to admission. It is notable however that since this episode, she has had no further seizures despite stopping all medication.

\section{Discussion}

The features observed in our patient of intractable epilepsy, respiratory depression, plasma hyperosmolality, a metabolic acidosis and rapid recovery, are consistent with propylene glycol poisoning. ${ }^{2-7}$ However, in most cases reported, the diagnosis was made retrospectively, after weeks to months of symptoms later attributed to propylene glycol. ${ }^{2-4,6,7}$

When admitted our patient was in status epilepticus and developed respiratory depression soon after. Although the arterial pH was initially normal, 
when tested several hours later, the $\mathrm{pH}$ had dropped to 7.29 and a metabolic acidosis had developed. The combination of the above raised the possibility of poisoning with an alcohol and the serum osmolality was measured and the osmolal gap calculated retrospectively in the plasma sample taken on admission.

The osmolal gap does not usually exceed $10 \mathrm{mmol} / \mathrm{kg} \mathrm{H}_{2} \mathrm{O}$ except in three clinical situations: (1) reduced plasma water because of hyperlipidaemia or hyperproteinaemia; ${ }^{10}$ (2) the presence of endogenous solutes such as amino acids in multiple organ failure; ${ }^{9}$ and (3) exogenous solutes such as mannitol and alcohols. ${ }^{10}$ The usefulness of the osmolal gap in screening for drug overdose is limited to toxins with low molecular weight such as ethanol $^{11}$ and furthermore the normal osmolal gap does not exclude their presence since small amounts will not cause a significant rise. ${ }^{12}$ In general, this investigation can provide vital information when excess of an alcohol in blood is suspected, but it is not often considered as a first line investigation. However, because of the rapid metabolism of most alcohols, unless measured at an early opportunity, the transiently raised osmolal gap may be missed. Although there are few pharmacokinetic data for propylene glycol, ${ }^{3}$ the plasma half-life may be as short as five hours. ${ }^{2}$ In our patient, the plasma concentration fell from $4 \mathrm{~g} / 1$ to less than $0.1 \mathrm{~g} / 1$ within 6 hours. This indicates an even shorter half-life possibly caused by enzyme induction secondary to chronic anticonvulsant treatment.

Propylene glycol is partly excreted unchanged by the kidneys, and partly metabolized to lactate, pyruvate and acetone. ${ }^{1}$ Although no suitable samples were available for lactate and pyruvate analysis in our patient at the time when the metabolic acidosis was observed, in the absence of other causes for the acidosis it is likely that the concentration of these two acids would have been raised. It is not surprising that when admitted the patient was not acidotic, since acidosis is not an early biochemical abnormality following ingestion of an alcohol. Consequently the anion gap would be normal in the presence of a high osmolal gap. On subtracting the osmotic effect due to $0.9 \mathrm{~g} / 1$ ethanol, the osmotic activity of propylene glycol in our patient appeared to be $81 \%$, thus nearer the $100 \%$

\section{References}

1. Ruddick, J.A. Toxicology, metabolism and biochemistry of 1,2-propanediol. Toxicol Appl Pharmacol 1972, 21: 102-111.

2. Kelner, M.J. \& Bailey, D.N. Propylene glycol as a cause of lactic acidosis. 'J Analyt Toxicol 1985, 9: $40-42$. observed by some workers ${ }^{3}$ than the $16 \%$ observed by others. ${ }^{13}$ This suggests that the rise in osmolal gap due to propylene glycol is nearly equivalent to the molar concentration, and that the magnitude of the osmolal gap may be of predictive value. Even if at that stage there had been an acidosis the excess of unmeasured anion would not have significantly contributed to the hyperosmolality. ${ }^{9}$

Endogenous propylene glycol, thought to be derived from ethanol metabolism, has been found in blood from alcoholics and volunteers following ingestion of spirits, but at a concentration a thousandfold lower than the corresponding ethanol level in the same sample. ${ }^{14}$ As this was not the case in our patient, we believe propylene glycol was selfadministered as she has had no seizures for a year following cessation of all anticonvulsant medication. Propylene glycol was present in fruit juice found at her flat, but at a concentration not thought to have been sufficiently high to account for the observed blood level, unless consumed in great excess. However, only $100-200 \mathrm{ml}$ of neat propylene glycol would have to be taken or given for a plasma concentration of $4 \mathrm{~g} / 1$ to be reached. According to the World Health Organization, ${ }^{15}$ a daily intake of up to $25 \mathrm{mg} / \mathrm{kg}$ body weight of propylene glycol is permitted, and the alcohol is used widely in consumer products. ${ }^{1}$ Our patient, as well as a previous case, ${ }^{5}$ illustrate the possibility that unidentified products may contain sufficient amounts of propylene glycol to enable toxic plasma levels to be achieved following self-administration. We recommend that plasma osmality and osmolal gap be considered first line investigations in patients presenting with an unexplained metabolic acidosis, and with cerebral signs and symptoms.

\section{Acknowledgements}

We wish to thank Dr K. Zilkha, (National Hospitals for Nervous Diseases, London) for his kind permission to report the case, the Mass Spectroscopy Unit, Department of Chemical Pathology, (Hospital for Sick Children, London), who kindly carried out confirmatory tests for the detection of propylene glycol, Mrs Marina Shaw (National Hospitals for Nervous Diseases, London), for her invaluable assistance in the preparation of the manuscript and Mr S.F. Alban-Davies for helpful discussions.

3. Flinger, C.L., Jack, R., Twiggs, G.A. \& Raisys, V.A. Hyperosmolality induced by propylene glycol. A complication of silver sulfadiazine therapy. JAMA 1985 , 253: 1606-1609. 
4. Demey, H., Daelemans, R., De Broe, M.E. \& Bossaert, L. Propylene glycol intoxication due to intravenous nitroglycerin. Lancet 1984, ii: 1360.

5. Cate, J.C. \& Hendrick, R. Propylene glycol intoxication and lactic acidosis. $N$ Engl $J$ Med 1980, 303: 1237.

6. Martin, G. \& Finberg, L. Propylene glycol: a potentially toxic vehicle in liquid dosage form. $J$ Pediatr 1970, 77: 877-878.

7. Arulanantham, K. \& Genel, M. Central nervous system toxicity associated with ingestion of propylene glycol. J Pediatr 1978, 93: 515-516.

8. Flanagan, R.J., Dawling, S. \& Buckley, B.M. Measurement of ethylene glycol (ethane-1,2-diol) in biological specimens using derivitisation and gas-liquid chromatography with flame ionisation detection. Ann Clin Biochem 1987, 24: 80-84.

9. Inaba, H., Hirasawa, H. \& Mizuguchi, M. Serum osmolality gap in postoperative patients in intensive care. Lancet 1987, ii: 1331-1335.

10. Gennari, Y.F. Current concepts, serum osmolality, uses and limitations. $N$ Engl $J$ Med 1984, 310: 102-105.
11. Glasser, L., Sternglanz, P.D., Combie, J. \& Robinson, A. Serum osmolality and its applicability to drug overdose. Am J Clin Pathol 1973, 60: 695-699.

12. Smithline, N. \& Gardner, K.D., Jr. Gaps - anionic and osmolal. JAMA 1976, 236: 1594-1597.

13. Glasgow, A.M., Boeckx, R.L. Miller, M.K. et al. Hyperosmolality in small infants due to propylene glycol. Pediatrics 1983, 72: 353-355.

14. Rutstein, D.D., Nickerson, R.J., Vernon, A.A. et al. 2,3-Butanediol: An unusual metabolite in serum of severely alcoholic men during acute intoxication. Lancet 1983, i: 534-537.

15. World Health Organisation. Toxicological evaluation of certain food additives with a review of general principles and of specifications: 17th Report of the Joint/WHO Expert Committee on Food Additives. Technical Report Series; No. 539: World Health Organisation, Geneva, 1974. 